\title{
Anabases
}

ANABASES Traditions et réceptions de l'Antiquité

$20 \mid 2014$

Varia

\section{María Paz DE HOZ \& Gloria MORA (éd.), El Oriente griego en la península ibérica. Epigrafía e historia}

\section{Grégory Reimond}

\section{OpenEdition}

Journals

Édition électronique

URL : http://journals.openedition.org/anabases/5156

DOI : 10.4000/anabases.5156

ISSN : 2256-9421

Éditeur

E.R.A.S.M.E.

Édition imprimée

Date de publication : 1 novembre 2014

Pagination : 416-418

ISSN : 1774-4296

Référence électronique

Grégory Reimond, « María Paz de hoz \& Gloria moRA (éd.), El Oriente griego en la península ibérica. Epigrafía e historia », Anabases [En ligne], 20 | 2014, mis en ligne le 01 novembre 2014, consulté le 22 septembre 2020. URL : http://journals.openedition.org/anabases/5156 ; DOI : https://doi.org/ 10.4000/anabases.5156

Ce document a été généré automatiquement le 22 septembre 2020

(c) Anabases 


\title{
María Paz DE HOZ \& Gloria MORA (éd.), El Oriente griego en la península ibérica. Epigrafía e historia
}

\author{
Grégory Reimond
}

\section{RÉFÉRENCE}

María Paz DE HOZ \& Gloria MORA (éd.), El Oriente griego en la península ibérica. Epigrafía e historia, Madrid, Real Academia de la Historia, Bibliotheca Archaeologica Hispana 39, $2013,350 \mathrm{p}$.

60 euros / ISBN 978-84-96849-36-5

1 Depuis la fin du XIX ${ }^{\mathrm{e}}$ siècle, époque où les savants découvrent et définissent peu à peu la culture ibérique, la question des liens entre l'Orient grec et la péninsule, longtemps abordée à partir d'une posture hellénocentrique, a toujours été au cœur de l'historiographie sur l'Hispanie antique. D'une certaine façon, l'histoire ancienne de l'Espagne s'est écrite dans l'ombre de ces grands frères grecs, perçus comme des modèles indépassables. En somme, c'est la vision d'une culture périphérique et sous influence au sein de l'espace méditerranéen, perçu comme une mer grecque, qui a longtemps dominé. Or quelle place peut-on réellement donner aux Grecs et aux peuples gréco-orientaux dans la péninsule Ibérique? Telle est la question qui sert de fil conducteur au livre édité par la Real Academia de la Historia.

2 Publié sous la direction de María Paz de Hoz (université de Salamanque) et Gloria Mora (université autonome de Madrid), ce volume réunit quatorze études rédigées par les meilleurs spécialistes. En un peu plus de 350 pages, ils brossent un tableau détaillé et actualisé de la présence grecque et gréco-orientale dans la péninsule Ibérique, depuis la période archaïque jusqu'à l'époque wisigothique. Si les sources littéraires et archéologiques sont convoquées, les différents articles font la part belle aux documents épigraphiques, qui sont privilégiés car moins connus. Il s'agit « dès lors d'aborder ce 
thème selon des perspectives différentes, en confrontant les sources avec d'autres qui n'ont pas été autant étudiées ou systématiquement analysées. Le témoignage écrit, concrètement le matériel épigraphique grec, plus abondant qu'il n'y paraît à première vue, permet d'affronter l'étude de cette longue présence gréco-orientale par une autre voie, laquelle offre bien souvent une nouvelle approche ou même de nouveaux contenus » (Prólogo, p. 9).

Le volume s'ouvre sur une étude d'Adolfo Domínguez Monedero (université autonome de Madrid), qui revient sur le problème des sources et de leurs divergences: «Los primeros griegos en la Península Ibérica (s. IX-VI a. C.) : mitos, probabilidades, certezas » (p. 11-42). Les douze études suivantes répondent à un plan qui est à la fois thématique et chronologique.

4 Les périodes archaïque, classique et hellénistique sont essentiellement abordées à partir de l'analyse de la présence commerciale des Grecs dans la péninsule. En effet, la perspective de l'échange commercial constitue leur principale motivation, laquelle les pousse à s'aventurer dans l'Occident méditerranéen. L'étude des graffites mercantiles, des lettres sur plomb, des monnaies (qui permet également d'aborder la question des échanges culturels et religieux) et des timbres amphoriques est ainsi au cœur des travaux proposés par Javier de Hoz (Université Complutense de Madrid, «El comercio en época arcaica y clásica: los grafitos y las cartas de plomo », p. 43-60), Joaquim Tremoleda et Marta Santos (Musée d'Archéologie de Catalogne, «El comercio oriental en época helenística : los sellos anfóricos », p. 61-110) et $\mathrm{M}^{a}$ Paz García-Bellido (csic, «Los griegos de Iberia en época arcaica y clásica según datos metrológicos y numismáticos », p. 111-136).

5 Les cinq études relatives à la présence grecque dans la péninsule à l'époque romaine (qui avait jusque-là peu retenu l'attention des historiens) sont aussi l'occasion d'élargir le champ d'étude et d'explorer de nouveaux aspects de cette présence, toujours en privilégiant les sources épigraphiques. Outre les échanges commerciaux, les auteurs envisagent ainsi les échanges et apports culturels, artistiques et religieux : il s'agit des chapitres rédigés par Guadalupe López Monteagudo (CSIC, «Los mosaicos como documentos », p. 137-169), Joan Gómez Pallarès (université autonome de Barcelone, «Los mosaicos con inscripción griega en Hispania : datos y análisis », p. 171-184), José Beltrán Fortes (université de Séville, «Greco-orientales en la Hispania Republicana e imperial a través de las menciones epigráficas », p. 185-204), Mª Paz de Hoz (université de Salamanque, «Cultos griegos, cultos sincréticos y la inmigración griega y grecooriental en la Península Ibérica», p. 205-254) et de Pablo C. Díaz (université de Salamanque, «Los orientales y la llegada del cristianismo a la Península Ibérica », p. 255-262).

6 L'étude de Pablo C. Díaz relative à la diffusion du christianisme en Hispanie permet de faire le lien avec le dernier bloc chronologique centré sur le Bas-Empire et la période pendant laquelle la péninsule vit sous la domination des Wisigoths. Il regroupe les travaux de Margarita Vallejo Girvés (université d'Alcalá, «Bizancio y el Mediterráneo entre finales del siglo v y principios del siglo viII. Navegando por un mar romano ", p. 263-279), Jaime Vizcaíno Sánchez (université de Murcie, « Hispania y Oriente durante el período de ocupación bizantina (siglos VI-VII). La documentación arqueológica ", p. 281-305) et Josep Anton Remolà Vallverdú (Musée national archéologique de Tarragone, « Ánforas orientales tardías en Tarraco (siglos V-VII) », p. 307-330). 
7 Les auteures des deux derniers chapitres sur lesquels se clôt le volume sur L'Orient grec dans la péninsule Ibérique adoptent quant à elles une démarche historiographique. Gloria Mora (université autonome de Madrid) s'intéresse ainsi à «La presencia griega en España en la historiografía y el coleccionismo de Antigüedades (siglos XVI al XVIII) » (p. 331-345), tandis que $\mathrm{M}^{\mathrm{a}} \mathrm{Paz}$ de Hoz signe un chapitre en forme d'épilogue dans lequel elle revient sur les apports de chacun des auteurs à la question traitée ("Conclusiones : quince siglos de presencia griega en la península ibérica », p. 347-355). Une étude historiographique relative aux $\mathrm{XIX}^{\mathrm{e}}$ et $\mathrm{Xx}^{\mathrm{e}}$ siècles aurait mérité une place dans cette ultime section. C'est la seule réserve que nous formulerons sur ce nouveau volume de la Bibliotheca Archaeologica Hispana qui reste en tout point remarquable, qu'il s'agisse de la qualité scientifique des publications ou du soin apporté à son édition. C'est un bel objet appelé à devenir une œuvre de référence.

\section{AUTEURS}

GRÉGORY REIMOND

gregoryr1984@live.fr 